\title{
AUMENTO DA VIDA ÚTIL E MICROBIOLOGIA DA CARNE SUÍNA EMBALADA EM ATMOSFERA MODIFICADA ${ }^{1}$
}

\author{
Sérgio Borges MANO $^{2, *}$, Juan Antonio Ordóñez PEREDA'; Gonzalo Doroteu García de FERNANDO
}

\section{RESUMO}

Com o objetivo de avaliar o efeito da embalagem de carne suina em atmosfera modificada, obteve-se assepticamente amostras de lombo (Longissimus dorsi) de suino de aproximadamente $3 \times 3 \mathrm{~cm}$ que depois de lavadas em solução salina $(0,35 \%)$ estéril, foram introduzidas em bolsas de plástico (Cryovac BB4L) de baixa permeabilidade. Dividiram-se em 4 lotes e se embalaram com aproximadamente 1,0L de ar $(100 \%)$, nitrogênio $(100 \%), 20 / 80$ e $40 / 60 \mathrm{CO}_{2} / \mathrm{O}_{2}$ e se termo-selaram. Finalmente, cada lote se subdividiu em 2 , armazenando-se a 1 e $7^{\circ} \mathrm{C}$. Durante o armazenamento tomaram-se amostras determinando-se a composição da atmosfera, o pH e a composição da microbiota (microbiota total, bactérias lácticas, Enterobacteriaceae, Brochothrix thermosphacta e contagens em ágar pseudomonas). Os parâmetros de crescimento (fase de latência e tempo de duplicação) dos microrganismos foram determinados mediante a equação de Gompertz. Os resultados demonstraram que a vida útil da carne suína é prolongada quando se armazena em atmosferas modificadas. As atmosferas enriquecidas com $\mathrm{CO}_{2}$ e a $1^{\circ} \mathrm{C}$ mostraram uma maior eficácia. As atmosferas com $\mathrm{CO}_{2}$, mantiveram o pH das amostras constante durante todo o periodo de armazenamento. A 1 e $7^{\circ} \mathrm{C}$, as fases de latência e os tempos de duplicação da microbiota total foram progressivamente maiores na seguinte ordem: atmosfera de ar (100\%), $\mathrm{N}_{2}(100 \%), 20 / 80$ e $40 / 60 \mathrm{CO}_{2} / \mathrm{O}_{2}$. Pode-se concluir que, tanto a 1 como a $7^{\circ} \mathrm{C}$, a utilização das atmosferas modificadas retardou o crescimento das bactérias alterantes da carne suína, favorecendo o prolongamento da vida útil, principalmente nas atmosferas $\mathrm{com} \mathrm{CO}_{2}$.

Palavras-chave: atmosfera modificada; carne suina; vida útil.

\section{SUMMARY}

SHELF LIFE EXTENSION AND MICROBIOLOGY OF PORK MEAT PACKAGED IN MODIFIED ATMOSPHERE. The objective of the present study was to evaluate the effect of modified atmospheres on refrigerated pork meat (Longissimus dorsi). Pork meat was cut into ca. $1 \mathrm{~cm}$ thick slices of $9 \mathrm{~cm}^{2}$, introduced in Cryovac type BB4L bags, characterized by its low gas permeability, and divided into four batches. The bags of each batch were filled with either $1.0 \mathrm{~L}$ of air $(100 \%)$, nitrogen $(100 \%), 20 / 80$ or $40 / 60 \mathrm{CO}_{2} / \mathrm{O}_{2}$ and finally sealed. Samples were subdivided into two batches and stored in walk-in cold rooms at 1 and $7^{\circ} \mathrm{C}$. Samples were taken at different days of storage and pH and gas concentration $\left(\mathrm{CO}_{2} / \mathrm{O}_{2} / \mathrm{N}_{2}\right)$ were determined. Likewise, total viable, lactic acid bacteria, Enterobacteriaceae, Brochothrix thermosphacta and Pseudomonas were counted. Bacterial growth parameters were assessed using Gompertz equations. As expected, modified atmosphere packaging extended the pork meat shelf life. However, modified atmospheres enriched with $\mathrm{CO}_{2}$ and at $1^{\circ} \mathrm{C}$ showed a greater effectiveness. The samples conserved in MAP enriched in $\mathrm{CO}_{2}$, as much to 7 as to $1^{\circ} \mathrm{C}$, maintained the constant $\mathrm{pH}$ during the period of storage. At 1 and $7^{\circ} \mathrm{C}$ the lag phases and the duplication times of the total microbiota were progressively larger in the following order: air $(100 \%), \mathrm{N}_{2}(100 \%), 20 / 80$ and $40 / 60 \mathrm{CO}_{2} / \mathrm{O}_{2}$. In accordance with the results, it can be concluded that, by as much to 1 as to $7^{\circ} \mathrm{C}$, the use of the modified atmospheres slowed the growth of the spoilage bacteria of pork meat, favoring the extension of the useful life, mainly in the MAP enriched with $\mathrm{CO}_{2}$.

Keywords: modified atmospheres; pork meat; shelf life.

\section{1 - INTRODUÇÃO}

O abate de suínos, influenciado no Brasil pela safra de cereais, especialmente o milho, tem sido regular nos meses de maio a dezembro e vem em socorro ao abastecimento de carne bovina que escasseia em número e em tonelagem a partir de agosto, queda esta que persiste até dezembro. Conquanto a produção de carnes de suínos não tenha evoluído significativamente nos últimos 20 anos possivelmente em parte devido a fatores de ordem sanitária, o rebanho de grande parte do território nacional tem evoluído zootecnicamente, através da substituição do primitivo porco produtor de banha pelo tipo produtor de carne. Graças à tecnificação da suinocultura e à evolução tecnológica da indústria de produtos suínos, além de ter-se sofisticado em favor dos cortes nobres, o consumo de carne in natura, também se diversificou e qualificou-se a elaboração de produtos suínos industrializados [41].
De acordo com o IBGE, em sua pesquisa trimestral de abate de animais realizada em 1999, as estatísticas da produção de carne suína no Brasil mostram um incremento de 800 mil toneladas nos últimos 10 anos, passando de 1,05 para 1,86 milhões de toneladas de carne, representando um aumento de 27,6 milhões de dólares na balança comercial brasileira neste periodo.

Já se demonstrou, também, que o acondicionamento de alimentos frescos (carne e peixe) em atmosfera modificada prolonga a vida útil desses alimentos $[1,5,6,8$, $12,14,15,18,19,20,22,26,29,32,34,35,42,43$, $46,47]$. Entretanto, ainda não se conhece o desenvolvimento da microbiota alterante da carne suína armazenada nestas condições.

O oxigênio do ar é um fator que influi poderosamente na vida útil de muitos alimentos devido ao seu efeito químico, e permite o crescimento dos microrganismos aeróbios. São diversos os sistemas clássicos de conser-

\footnotetext{
${ }^{1}$ Recebido para publicação em 20/09/99. Aceito para publicação em 17/10/01.

${ }^{2}$ Departamento de Tecnologia dos Alimentos, Faculdade de Veterinária, UFF. CEP 24230-340 - Niterói/RJ - Brasil

${ }^{3}$ Departamento de Nutrición y Bromatología III (Higiene y Tecnología de los Alimentos), Facultad de Veterinaria, UCM. 28040 - Madrid - España.

* A quem a correspondência deve ser enviada.
} 
vação, porém se está procurando melhorar, já que estes sistemas não atingem todas as expectativas da indústria alimentar. Entre estas tentativas, está a embalagem em atmosfera modificada, que consiste na embalagem hermética de um alimento, em um material plástico de alta barreira, no qual substitui-se o ar por um gás ou mistura de gases.

Portanto, os objetivos do presente estudo foram avaliar o efeito da embalagem da carne suína (Longissimus dorsi) em atmosfera modificada e estudar o crescimento dos microrganismos responsáveis pela sua alteração.

\section{2 - MATERIAL E MÉTODOS}

Matéria-prima: o corte cárneo correspondente ao lombo (Longissimus dorsi) foi transportado em bolsa plástica no interior de um recipiente hermético isotérmico com gelo. O sistema de colheita do lombo utilizado nesta investigação (separação do corte primário e desossa) foi cuidadosamente conduzido com auxilio de material previamente esterilizado.

Com a chegada das peças de carne ao laboratório, procedia-se imediatamente à retirada do excesso de gordura superficial e porções de outros músculos que acompanhavam o L. dorsi. Posteriormente, cortava-se o músculo transversalmente em pedaços de aproximadamente $0,5 \mathrm{~cm}$ de espessura com uma faca previamente flambada. Do centro desta porção obtinha-se assepticamente uma amostra de aproximadamente $18 \mathrm{~cm}^{2}$ de superficie.

As amostras foram embaladas em bolsas BB4L (uma amostra por bolsa) com as seguintes atmosferas: $100 \%$ ar, $100 \%$ nitrogênio, $20 / 80 \mathrm{CO}_{2} / \mathrm{O}_{2}$ ou $40 / 60 \mathrm{CO}_{2} / \mathrm{O}_{2}$.

A relação utilizada de gás/amostra foi de $200: 1$, o que correspondeu a $\sim 1$, OL de gás por bolsa.

O número de bolsas foi calculado de acordo com a temperatura de incubação e a atmosfera utilizada.

A incubação das amostras foi realizada em câmaras frigorificas reguladas a 1 ou $7^{\circ} \mathrm{C}$.

Diariamente ou em dias alternados, de acordo com a temperatura de incubação, a atmosfera utilizada e os resultados dos dias anteriores, realizaram-se as análises microbiológicas.

Antes de embalar as amostras, colheram-se, aleatoriamente, duas amostras para determinar o $\mathrm{pH}$ e a carga microbiana inicial.

As amostras mantidas em atmosferas de $100 \%$ ar, $100 \%$ nitrogênio, 20/80 $\mathrm{CO}_{2} / \mathrm{O}_{2}$ e $40 / 60 \mathrm{CO}_{2} / \mathrm{O}_{2}$ transportavam-se ao laboratório nas mesmas bolsas plásticas usadas para a incubação. Depois de analisar-se a composição dos gases das bolsas mediante o analisador combinado de gases $\left(\mathrm{O}_{2}+\mathrm{CO}_{2}\right)$, procedia-se à abertura em campana de fluxo laminar.

Introduziam-se as amostras em bolsas estéreis para "Stomacher" com $25 \mathrm{~mL}$ de solução salina esterilizada e a seguir realizava-se sua homogeneização durante $1 \mathrm{~min}$.

Os meios de cultura empregados para as contagens foram: ágar padrão para contagem em placa (PCA); ágar de Man, Rogosa e Sharpe (MRS) [27], ajustando o pH a 5,6 com ácido acético e utilizando ágar em dupla capa; ágar violeta roxo bílis glicose (VRBG); ágar sulfato de estreptomicina (50\%), cicloheximida (5\%), acetato de tálio (5\%) (STAA fornecido por Oxoid, para a contagem de Brochothrix thermosphacta), e; ágar seletivo para Pseudomonas (PSD) com "Pseudomonas C-F-C Suplemento Seletivo" (cetrimida a $1 \%$, fucidina a $1 \%$ e cefaloridina a $5 \%)$ fornecido por Oxoid.

A preparação dos meios de cultura foi realizada de acordo com as instruções das casas fornecedoras (Difco e Oxoid). A esterilização se realizava a $121^{\circ} \mathrm{C}$ durante $15 \mathrm{~min}$. No caso dos meios STAA e ágar PSD, adicionouse o suplemento específico de forma asséptica depois da esterilização do meio.

Prepararam-se diluições decimais em solução salina $(0,85 \%$ de $\mathrm{NaCl})$ esterilizada a partir das amostras.

De acordo com o número de microrganismos viáveis esperados, semeou-se $1 \mathrm{~mL}$ das diluições desejadas nas placas de Petri. A seguir, adicionou-se a quantidade de ágar a aproximadamente $45^{\circ} \mathrm{C}$ para cobrir o fundo da placa; depois, agitava-se suavemente para homogeneizar a amostra e o ágar. Nas contagens de bactérias lácticas em ágar MRS, uma vez solidificado, adicionava-se outra camada do meio para criar condições microaerófilas que favorecem o crescimento dos microrganismos.

Em todos os casos semearam-se 2 placas de cada diluição.

As placas foram incubadas invertidas em câmara mantidas às seguintes temperaturas durante os tempos especificados: ágar para contagem em placa (PCA) a $32^{\circ} \mathrm{C}$, de 24 a 48 horas; ágar para contagem de bactérias lácticas (MRS) a $32^{\circ} \mathrm{C}$, de 48 a 72 horas; ágar para contagem de enterobactérias (VRBG) a $32^{\circ} \mathrm{C}$ durante 24 horas; ágar para contagem de $B$. thermosphacta (STAA) a $24^{\circ} \mathrm{C}$, de 48 a 72 horas, e; ágar para contagem de Pseudomas spp. (PSD) a $24^{\circ} \mathrm{C}$, de 48 a 72 horas.

Depois do período de incubação correspondente, efetuou-se a contagem das colônias presentes nas placas, considerando-se as placas que continham entre 30 e 300 colônias. A contagem dividia-se por 18 (área total da amostra em $\mathrm{cm}^{2}$ ), e assim, os resultados finais foram expressos em log $\mathrm{UFC} / \mathrm{cm}^{2}$ de amostra.

Após a colheita de amostra para as determinações microbiológicas, foram efetuadas, por amostra, 5 determinações de $\mathrm{pH}$ introduzindo o eletrodo na própria bolsa de "Stomacher", aonde se homogeneizava a amostra. $\mathrm{O}$ valor do $\mathrm{pH}$ foi obtido por média aritmética das medidas.

A análise da atmosfera que rodeava a carne foi realizada justamente antes da abertura da bolsa para a análise microbiológica.

A determinação quantitativa dos componentes da atmosfera foi feita com um analisador combinado de gás $\left(\mathrm{O}_{2}+\mathrm{CO}_{2}\right)$ marca "Abiss" mod. GT12, perfurando-se 
a bolsa com uma agulha unida ao analisador, esperando-se alguns segundos até que a medida dos gases estabilizasse.

O nitrogênio foi estimado por diferença entre 100\% e a soma das porcentagens de $\mathrm{O}_{2}$ e $\mathrm{CO}_{2}$, assumindo-se que a atmosfera compunha-se somente destes 3 gases.

O crescimento da população bacteriana foi descrito mediante a equação modificada de Gompertz [17]. Utilizou-se para tal, um programa computacional idealizado pelo Dr. József Baranyi do "Institute of Food Research (Reading Laboratory, UK)”.

\section{3 - RESULTADOS E DISCUSSÃO}

\section{1 - Mudança na composição do gás}

A composição das atmosferas não se modificou em nenhuma amostra durante os distintos periodos de armazenamento (dados não apresentados).

Não são muitos os trabalhos, cujo objetivo tenha sido o estudo das variações da composição dos gases durante o armazenamento de carne em atmosferas modificadas. Ademais, em algumas situações apresentaramse resultados contraditórios. Enquanto que alguns autores [44] indicam que a concentração de $\mathrm{CO}_{2}$ diminui durante o armazenamento de carne suina (a $\left.2^{\circ} \mathrm{C}\right) \mathrm{em}-$ balada em atmosferas inicialmente compostas por 20 e $40 \%$ de $\mathrm{CO}_{2}$ com 5 e $10 \%$ de $\mathrm{O}_{2}$, outros [47] asseguram que, nas mesmas condições, os niveis de $\mathrm{CO}_{2}$ aumentam. Por outro lado, já se constatou [13] uma diminuição de $\mathrm{O}_{2}$ e um aumento de $\mathrm{CO}_{2}$ durante o armazenamento a $4^{\circ} \mathrm{C}$ de carne suína cozida embalada em aerobiose, observando também uma diminuição do $\mathrm{CO}_{2}$ nas amostras embaladas em atmosfera modificada. Resultados similares foram observados em carne fresca de suíno [32, 46].

Como já comentado no princípio deste item, neste estudo a atmosfera não se modificou, ou seja, com o sistema de medida de gases aqui utilizado, não se observou nenhuma variação. A sensibilidade do analisador de gases (Abiss mod. GT12) não foi suficiente para medir pequenas variações que, certamente aconteceram, principalmente devido à atividade microbiana, atividade bioquímica da carne e permeabilidade do plástico. Outro fator decisivo foi a relação volume de gás/ massa de alimento, em torno de 100/1, enquanto que os niveis comerciais recomendados são da ordem de 2 / 1 [44] a 3/1 [21], obviamente por economia de espaço. Esta relação $(100 / 1)$, no presente estudo, tão diferente das práticas comerciais teve o objetivo de evitar que a modificação da atmosfera durante o armazenamento mascarasse o efeito da própria atmosfera no comportamento dos microrganismos psicrotróficos. Em outras palavras, com os meios de que se dispunha, se pretendeu criar condições próximas à das atmosferas controladas, o que, em efeito, foi o que ocorreu.

Resumidamente, pode-se dizer que, ainda que seja normal observar modificações na composição da atmosfera que rodeia o alimento, principalmente, na- queles com maior atividade metabólica (p.e. hortaliças e frutas, devido à atividade respiratória das mesmas), no presente trabalho não foram observadas variações.

\section{2 - Evolução do pH}

Todas as amostras de carne aqui utilizadas tiveram pHs similares, com valores médios de 5,4. Apesar deste pH final ser baixo, não se pode considerar como carne PSE, pois houve o acompanhamento do $\mathrm{pH}$ da carcaça durante as 24 horas de resfriamento, observando-se uma queda lenta e progressiva.

No presente trabalho, não foram observadas variações no $\mathrm{pH}$ ao princípio das experiências (Figuras 1 e 2), ainda que se encontraram diminuições deste parâmetro como conseqüência da solubilidade do $\mathrm{CO}_{2}$ nos alimentos $[7,8,32]$. Sem dúvida, em outras ocasiões não se detectaram variações, como em lombo cozido de suíno armazenado a $20^{\circ} \mathrm{C}$ [13]. Neste caso, o valor constante do $\mathrm{pH}$ durante a experiência pode explicar-se facilmente pela menor solubilidade do $\mathrm{CO}_{2}$ a esta relativamente alta temperatura (a $4^{\circ} \mathrm{C}$, se apreciou uma pequena diminuição do $\mathrm{pH}$ ) ou devido à perda de água durante o tratamento térmico, o que dificulta a solubilização do $\mathrm{CO}_{2}$. Mas, em outros casos como o presente, não cabem estas explicações, já que o alimento não se tratou termicamente e armazenou-se a temperaturas de refrigeração. Não obstante, diversas experiências $[2,9,10,15$, $26,45]$ mostram a invariabilidade do $\mathrm{pH}$. Provavelmente, estes resultados devam-se à capacidade tampão dos componentes da carne, que podem ser suficientes para inibir o efeito do $\mathrm{CO}_{2}$ solubilizado.

Em contrapartida, quando o alimento é mantido em aerobiose, é normal que o $\mathrm{pH}$ aumente, coincidindo com as contagens totais superiores a $10^{7} \mathrm{UFC} / \mathrm{cm}^{2}$ e sua alteração (Figuras 1 e 2). Estas mudanças se devem, possivelmente, à formação de substâncias básicas derivadas do crescimento de pseudomonas e de outros microrganismos afins.

No presente trabalho, o $\mathrm{pH}$ da maior parte das amostras embaladas em atmosfera modificada não variou ao longo de todo o tempo que durou as diferentes experiências. Não obstante, também se detectaram certos aumentos dos valores de $\mathrm{pH}$ em algumas amostras embaladas em atmosfera modificada, ainda que sempre menos evidentes que as observadas em carne embalada aerobicamente.

\section{3 - Microbiota total (MT)}

\subsection{1 - Contagem inicial}

Os niveis da MT ao principio das experiências foram baixos, sempre inferiores a $10^{3} \mathrm{UFC} / \mathrm{cm}^{2}$ (Tabelas $1 e$ 2), já que as peças de carne (lombos) foram adquiridas diretamente nos matadouros, preparando-se as amostras em laboratório, com medidas higiênicas apropriadas. Estas contagens iniciais baixas refletem as boas condições de manipulação das amostras, muito melhores que as habitualmente encontradas nos matadouros 
ou salas de desossa, aonde se encontram taxas mais elevadas. Como se pode observar em alguns casos, as contagens iniciais das amostras armazenadas a 1 e $7^{\circ} \mathrm{C}$ não foram iguais. Isto ocorreu devido à impossibilidade de partir de uma mesma matéria-prima, devido à limitação de espaço nos armários frigoríficos, ou da impossibilidade de manipular um número elevado de amostras.

TABELA 1. Vida útil e parâmetros de crescimento da microbiota da carne suina (Longissimus dorsi) embalada em diferentes atmosferas e mantida a $1^{\circ} \mathrm{C}$ durante 24 (ar 100\%), $34\left(\mathrm{~N}_{2}\right.$ $100 \%)$ ou 54 dias $\left(\mathrm{CO}_{2} / \mathrm{O}_{2} 20 / 80, \mathrm{CO}_{2} / \mathrm{O}_{2} 40 / 60\right)$.

\begin{tabular}{|c|c|c|c|c|c|c|c|}
\hline Atmosferas & V.U. & PARÂMETROS & M.A.T. & B.L. & ENTER. & Br. th. & PSD \\
\hline & & C.I. & 2,5 & 1,9 & 1,1 & 1,1 & 2,6 \\
\hline \multirow[t]{3}{*}{$\operatorname{Ar}(100 \%)$} & 15 & F.L. & 6,2 & 3,2 & 7,7 & 3,5 & 2,6 \\
\hline & & g & 0,7 & 1,6 & 0,6 & 0,9 & 0,8 \\
\hline & & C.F.E. & 9,4 & 5,4 & 7,8 & 7,7 & 9,4 \\
\hline \multirow[t]{3}{*}{$\mathrm{N}_{2}(100 \%)$} & 34 & F.L. & 9,5 & 8,8 & 9,5 & 9,2 & 7,3 \\
\hline & & g & 1,5 & 1,7 & 1,5 & 0,9 & 2,9 \\
\hline & & C.F.E. & 7,0 & 5,4 & 5,7 & 6,9 & 5,0 \\
\hline \multirow[t]{3}{*}{$\mathrm{CO}_{2} / \mathrm{O}_{2} 20 / 80$} & $>54 *$ & F.L. & 30,8 & 24,2 & C.N.D. & C.N.D. & C.N.D. \\
\hline & & g & 2,5 & 2,5 & - & - & - \\
\hline & & C.F.E. & 5,0 & 5,0 & 1,0 & 1,1 & 1,2 \\
\hline \multirow[t]{3}{*}{$\mathrm{CO}_{2} / \mathrm{O}_{2} 40 / 60$} & $>54 *$ & F.L. & 31,6 & 31,7 & C.N.D. & C.N.D. & C.N.D. \\
\hline & & $\mathrm{g}$ & 3,6 & 2,5 & - & - & - \\
\hline & & C.F.E. & 4,5 & 4,5 & 0,5 & 0,8 & 1,0 \\
\hline
\end{tabular}

B.L. - Bactérias lácticas (MRS pH 5,6 em dupla capa a $32^{\circ} \mathrm{C}, 48 \mathrm{~h}$ ).

Br. th. - Brochothrix thermosphacta (STAA a $20^{\circ} \mathrm{C}, 72 \mathrm{~h}$ ).

C.N.D. - Crescimento não detectado.

ENTER. - Enterobactérias (VRBG a $32^{\circ} \mathrm{C}, 48 \mathrm{~h}$ )

F.L. - Fase de latência (dias).

g - Tempo de duplicação (dias).

PSD - Microrganismos crescidos em meio seletivo para Pseudomonas spp. a $20^{\circ} \mathrm{C}$, $72 \mathrm{~h}$.

C.F.E. - Contagem em fase estacionária ou quando C.N.D., ao final do armazenamento.

mento.

C.I. - Contagem inicial $\left(\log \mathrm{UFC} / \mathrm{cm}^{2}\right)$.
V.U. - Vida útil (dias necessários para que a contagem de M.A.T. alcance o valor de $\left.10^{7} \mathrm{UFC} / \mathrm{cm}^{2}\right)$

* - A taxa final foi inferior a $10^{7} \mathrm{UFC} / \mathrm{cm}^{2}$ depois de 54 dias de armazenamento.

TABELA 2. Vida útil e parâmetros de crescimento da microbiota da carne suina (Longissimus dorsi) embalada em diferentes atmosferas e mantida a $7^{\circ} \mathrm{C}$ durante 12 (ar 100\%), $16\left(\mathrm{~N}_{2}\right.$ $100 \%)$ ou 28 dias $\left(\mathrm{CO}_{2} / \mathrm{O}_{2} 20 / 80, \mathrm{CO}_{2} / \mathrm{O}_{2} 40 / 60\right)$.

\begin{tabular}{|c|c|c|c|c|c|c|c|}
\hline AtMosferas & V.U. & PARÂMETROS & M.A.T. & B.L. & ENTER. & Br. th. & PSD \\
\hline & & C.I. & 2,7 & 1,9 & 1,2 & 0,8 & 3,0 \\
\hline \multirow[t]{3}{*}{ Ar $(100 \%)$} & 6 & F.L. & 4,1 & 3,0 & 3,3 & 2,5 & 1,1 \\
\hline & & g & 0,2 & 0,3 & 0,2 & 0,3 & 0,3 \\
\hline & & C.F.E. & 9,6 & 5,3 & 8,6 & 7,8 & 9,2 \\
\hline \multirow[t]{3}{*}{$\mathrm{N}_{2}(100 \%)$} & 9 & F.L. & 5,9 & 4,3 & 3,5 & 4,2 & 2,5 \\
\hline & & g & 0,3 & 0,5 & 0,4 & 0,5 & 0,5 \\
\hline & & C.F.E. & 7,0 & 6,1 & 6,5 & 6,2 & 5,7 \\
\hline \multirow[t]{3}{*}{$\mathrm{CO}_{2} / \mathrm{O}_{2} 20 / 80$} & 14 & F.L. & 6,8 & 5,5 & 8,0 & 4,8 & 10,3 \\
\hline & & g & 1,4 & 1,2 & 0,5 & 1,1 & 1,0 \\
\hline & & C.F.E. & 8,0 & 7,1 & 6,6 & 7,2 & 6,6 \\
\hline \multirow[t]{3}{*}{$\mathrm{CO}_{2} / \mathrm{O}_{2} 40 / 60$} & 20 & F.L. & 7,5 & 5,7 & C.N.D. & 5,0 & C.N.D. \\
\hline & & g & 1,5 & 0,7 & - & 1,5 & - \\
\hline & & C.F.E. & 7,1 & 7,1 & 1,8 & 5,0 & 3,2 \\
\hline
\end{tabular}

B.L. - Bactérias lácticas (MRS pH 5,6 em dupla capa a $32^{\circ} \mathrm{C}, 48 \mathrm{~h}$ ).

$\mathrm{Br}$. th. - Brochothrix thermosphacta (STAA a $20^{\circ} \mathrm{C}, 72 \mathrm{~h}$ ).

Br. th. - Brochothrix thermosphacta
C.N.D. - Crescimento não detectado.

ENTER. - Enterobactérias (VRBG a $32^{\circ} \mathrm{C}, 48 \mathrm{~h}$ ).

F.L. - Fase de latência (dias).

g-Tempo de duplicação (dias).

PSD - Microrganismos crescidos em meio seletivo para Pseudomonas spp. a $20^{\circ} \mathrm{C}$, $72 \mathrm{~h}$.

C.F.E. - Contagem em fase estacionária ou quando C.N.D., ao final do armazenamento.

C.I. - Contagem inicial $\left(\log \mathrm{UFC} / \mathrm{cm}^{2}\right)$.

V.I. - Contagem inicial $\left(\log \mathrm{UFC} / \mathrm{cm}^{2}\right)$.
Vida util (dias necessários para que a contagem de M.A.T. alcance o valor de $\left.10^{7} \mathrm{UFC} / \mathrm{cm}^{2}\right)$.

\subsection{2 - Fases de latência}

A fase de latência de uma população microbiana indica o tempo que demora essa população a iniciar a multiplicação ativamente. Neste trabalho, calculou-se este parâmetro através da equação de Gompertz. Infelizmente, a fase de latência não é constante nem mesmo em sistemas modelos, já que não depende somente da espécie microbiana, mas também da "história" do microrganismo ou grupo microbiano em questão, assim que, para se padronizar a fase de latência de uma cultura pura, tem-se que padronizar estritamente o procedimento. Partindo desta afirmação, deduz-se que este parâmetro de crescimento em Microbiologia de Alimentos, ainda que importante na prática (quanto maior, maior a vida-de-prateleira do alimento), é praticamente imprevisivel, já que é quase impossivel conhecer a procedência dos microrganismos, qual a temperatura que se encontrava antes de chegar ao alimento, quanto tempo estava presente no alimento, etc. Portanto, ainda que resulte fácil a determinação da fase de latência, o conhecimento deste dado tem uma importância relativa, já que não se conhecem as condições em que se encontravam os microrganismos que estavam presentes no alimento, e, portanto, se desconhece os parâmetros que a determinam. Além de que, quando se conhece este dado, a microbiota já iniciou seu crescimento, e saber neste momento o tempo que tardou em iniciar seu desenvolvimento carece de importância.

Não obstante, sempre é possível fazer algumas generalizações. Quanto mais baixa a temperatura de armazenamento, mais prolongada é a fase de latência; da mesma maneira, quanto mais seletiva é a atmosfera, maior é o tempo para a microbiota começar a sua multiplicação. Estas afirmações podem ser observadas claramente nas Tabelas 1 e 2, apesar de não haver constatação deste comportamento em carne de peru armazenada nas mesmas condições [29].

Em todo caso, este parâmetro sempre permite deduzir alguns fatos. Neste trabalho, as fases de latência foram úteis para comparar a adaptação de uma determinada microbiota nas atmosferas crescem, sempre e quando a contaminação inicial foi a mesma, já que as procedências eram as mesmas.

\subsection{3 - Tempos de duplicação}

Ao contrário do anterior, este parâmetro que define o crescimento de um microrganismo, é constante sempre que as condições são idênticas; isto é, mesma cepa, substrato, temperatura, atmosfera, etc. Neste item se discute os tempos de duplicação da MT desenvolvida, que foi uma população mais ou menos heterogênea e diferente.

Como era de se esperar, a $1^{\circ} \mathrm{C}$ os tempos de duplicação foram mais prolongados que a $7^{\circ} \mathrm{C}$. Também se esperava que a uma atmosfera mais seletiva a microbiota tardasse mais a multiplicar-se. Esta segunda afirmação se comprovou nas duas temperaturas estudadas (Tabelas 1 e 2), ainda que ocorreram di- 
ferenças notáveis entre 1 e $7^{\circ} \mathrm{C}$. Assim, os tempos de duplicação da MT desenvolvidos a $7^{\circ} \mathrm{C}$ (Tabela 2) foram de 0,2 dias em ar, 0,3 em $\mathrm{N}_{2}, 1,4$ em 20/80 $\mathrm{CO}_{2} / \mathrm{O}_{2}$ e 1,5 em $40 / 60 \mathrm{CO}_{2} / \mathrm{O}_{2}$, enquanto que a $1^{\circ} \mathrm{C}$ (Tabela 1$)$ foram de 0,7 dias em ar, 1,5 em $\mathrm{N}_{2}, 2,5 \mathrm{em} \mathrm{20/80} \mathrm{\textrm {CO } _ { 2 } /}$ $\mathrm{O}_{2}$ e 3,6 em 40/60 $\mathrm{CO}_{2} / \mathrm{O}_{2}$. No primeiro caso $\left(7^{\circ} \mathrm{C}\right)$, apenas se vislumbra o efeito inibidor das atmosferas modificadas, enquanto que a $1^{\circ} \mathrm{C}$ se torna evidente. A esse respeito, vale a pena comentar que o efeito do $\mathrm{CO}_{2}$ é mais intenso conforme se diminui a temperatura, assim que, é lógico que o efeito das atmosferas se fizesse mais evidente a 1 do que a $7^{\circ} \mathrm{C}$.
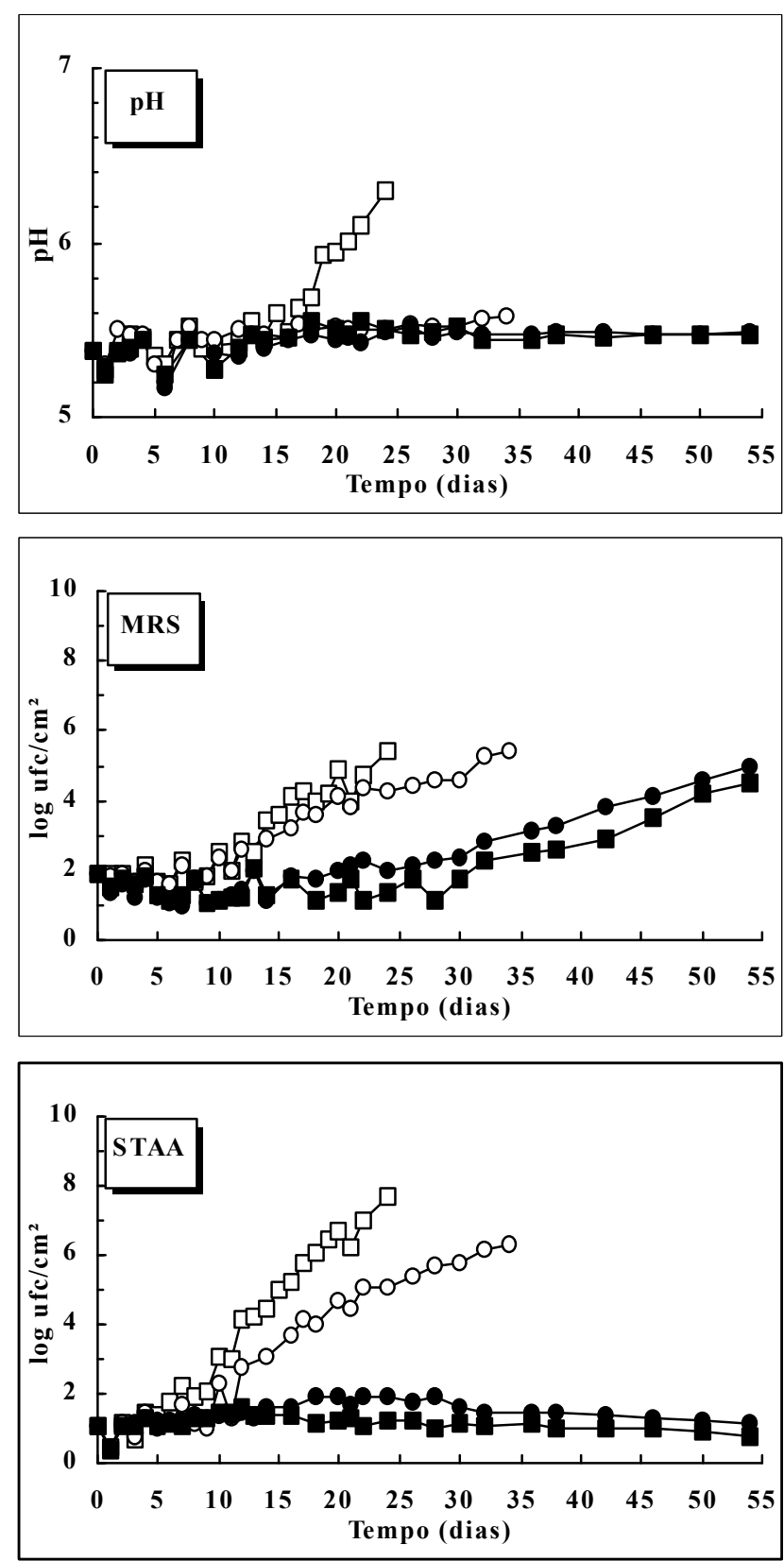

Não são muitos os trabalhos que determinaram o tempo de duplicação da MT em atmosfera modificada. Alguns autores [30] afirmaram que a microbiota aeróbia desenvolvida em costelas de porco a $4^{\circ} \mathrm{C}$ apresentavam tempos de duplicação, em uma experiência, de 0,8 dias em aerobiose e um pouco mais de 6 dias em todas as atmosferas estudadas: vácuo, 20/80 $\mathrm{CO}_{2} / \mathrm{N}_{2}, 40 / 60$ $\mathrm{CO}_{2} / \mathrm{N}_{2}$ e $40 / 10 / 50 \mathrm{CO}_{2} / \mathrm{O}_{2} / \mathrm{N}_{2}$, enquanto que em outras experiências obtiveram valores de 1,6 dias em ar e entre 4,6 e 4,9 dias nas outras atmosferas. Estes dados não contradizem em absoluto os encontrados no presente trabalho.
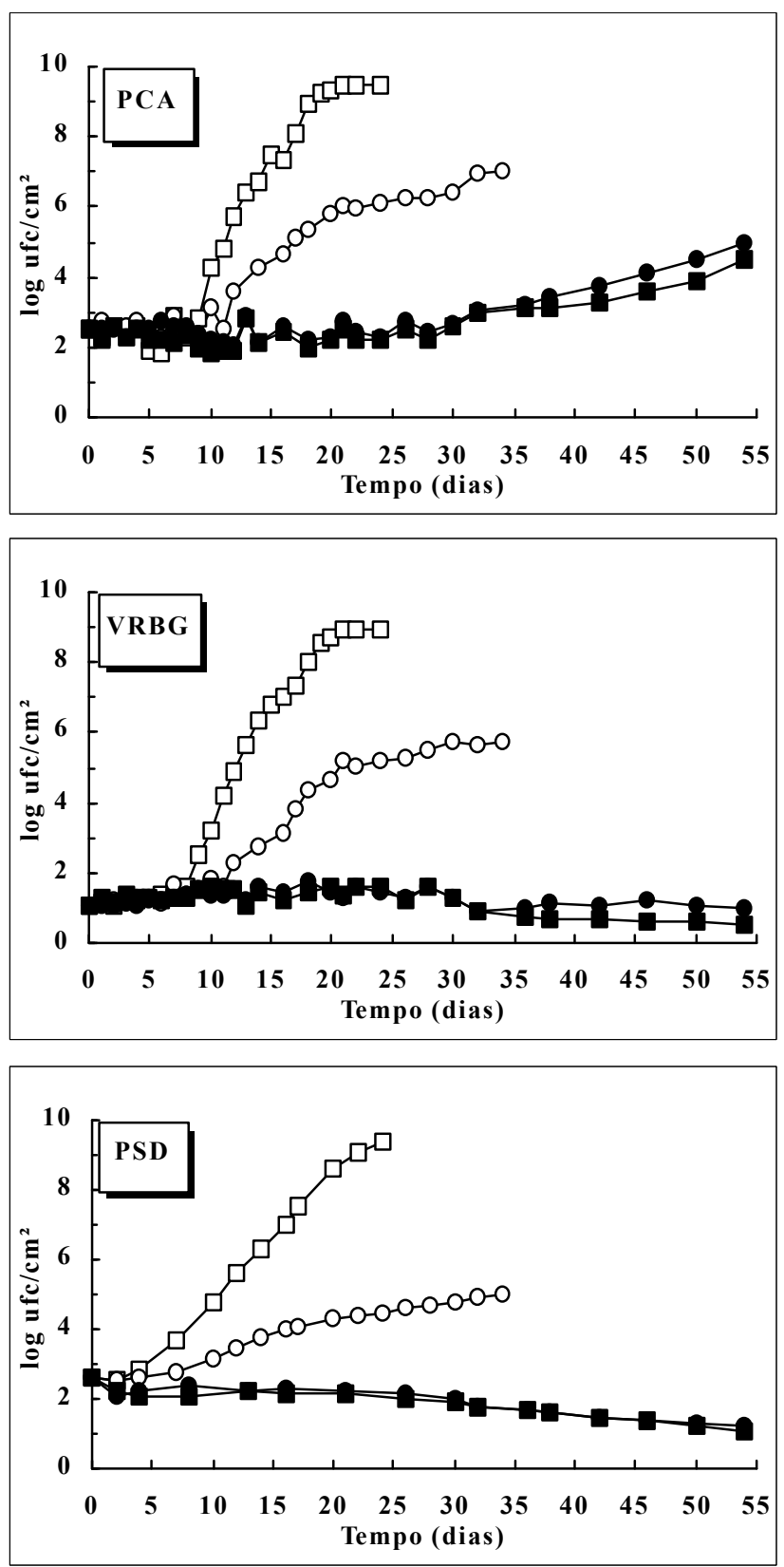

FIGURA 1. Evolução do pH, microbiota total (PCA), bactérias lácticas (MRS), enterobactérias (VRBG), Brochothrix thermosphacta (STAA) e Pseudomonas spp. (PSD) em carne suina armazenada em $100 \%$ ar (口), $100 \% \mathrm{~N}_{2}(\mathrm{O}), 20 / 80 \mathrm{CO}_{2} / \mathrm{O}_{2}(\bullet)$ e $40 / 60 \mathrm{CO}_{2} / \mathrm{O}_{2}$ (匹) a $1^{\circ} \mathrm{C}$. 


\subsection{4 - Taxa na fase estacionária}

O estudo das Tabelas 1 e 2 mostra, como era de se esperar, que as contagens da $\mathrm{MT}$ na fase estacionária foram maiores em ar, depois em $\mathrm{N}_{2}, 20 / 80 \mathrm{CO}_{2} / \mathrm{O}_{2} \mathrm{e}$ finalmente, menores em 40/60 $\mathrm{CO}_{2} / \mathrm{O}_{2}$. Isto é, conforme a atmosfera se faz mais seletiva, menor é o número de microrganismos ao final da fase exponencial de crescimento. Este fato conduz, em alguns casos, a não ultrapassar o nível da vida útil do ponto de vista microbiano; por exemplo, a MT das amostras embaladas em $20 / 80 \mathrm{CO}_{2} / \mathrm{O}_{2}$ e $40 / 60 \mathrm{CO}_{2} / \mathrm{O}_{2}$ mantidas a $1^{\circ} \mathrm{C}$ (Figura 1 - PCA) apresentaram tempos de duplicação de 2,5 e 3,6 dias respectivamente, e as contagens na fase estacionária foram de $10^{5}$ e $3,2 \times 10^{4} \mathrm{UFC} / \mathrm{cm}^{2}$, respectivamente (Tabela 1).

\section{4 - Vida útil}

Como era de se esperar, a modificação da atmosfera prolongou a vida útil da carne, seguindo a ordem lógica, de menos a mais prolongada: ar, $100 \%$ de $\mathrm{N}_{2}$, $20 / 80 \mathrm{CO}_{2} / \mathrm{O}_{2}$ e 40/60 $\mathrm{CO}_{2} / \mathrm{O}_{2}$. Obviamente, o efeito das atmosferas modificadas, sobretudo nas enriquecidas com $\mathrm{CO}_{2}$, foram potencializados ao reduzir-se a temperatura de armazenamento, como resultado do sinergismo existente entre estes dois fatores, como já constatado [5, 12, 14, 31, 34, 36]. Este efeito sinérgico impediu, em algum caso, que as contagens alcançassem as taxas de $10^{7} \mathrm{UFC} / \mathrm{cm}^{2}$ depois de armazenar a carne durante quase 2 meses (Tabela 1). Isto não significa que a carne embalada em atmosferas enriquecidas com $\mathrm{CO}_{2}$ possa ser armazenada por tempos tão prolongados a temperaturas de refrigeração. Temos que levar em conta que a vida útil de um alimento não pode ser determinada somente pelo ponto de vista microbiológico, mas também através das suas propriedades sensoriais, e nestes casos antes citados, a carne demonstrou um amaciamento excessivo depois dos prolongados tempos de armazenamento, provavelmente, causado por enzimas endógenas da própria carne.

É bem conhecido que um dos fatores decisivos na vida útil de um alimento é sua taxa microbiana inicial. Quanto maior, menor é a vida útil. Esta afirmação, é cumprida de forma relativa em alimentos embalados em atmosfera modificada, já que em alguns casos [28], ao se diminuir a carga inicial, também se reduz a vida útil. Este fato indica que mais importante que a concentração microbiana, pode ser a adaptação da microbiota presente às condições que encontra no alimento e que lhe permitirão multiplicar-se. Está claro que a presença maciça de microrganismos sensiveis ao $\mathrm{CO}_{2}$ em uma carne embalada em $40 \%$ deste gás, não conseguirá multiplicar-se e terá pouca significância na vida útil do produto. Em contrapartida, uma pequena quantidade de bactérias psicrotróficas resistentes ao $\mathrm{CO}_{2}$ poderá multiplicar-se ativamente e provocar a alteração do alimento em um tempo relativamente curto.

Do exposto até aqui, se pode resumir que a soma da refrigeração e embalagem em atmosfera modificada, além de impedir o crescimento de determinados micror- ganismos, prolongam as fases de latência (apesar da relativa importância deste parâmetro na prática) e os tempos de duplicação da microbiota que pode desenvolver-se nestas condições. Por esta razão, as atmosferas modificadas prolongam a vida útil da carne.

\section{5 - Bactérias lácticas}

De uma forma geral, as fases de latência das bactérias lácticas aumentaram conforme a atmosfera se fazia mais seletiva. Este efeito se comprovou mais claramente a 1 que a $7^{\circ} \mathrm{C}$. Um exemplo que ilustra esta afirmação pode ser visto na Tabela 1 , onde se recorrem os parâmetros de crescimento da microbiota crescida a $1^{\circ} \mathrm{C}$. As fases de latência foram: 3,2 dias em aerobiose, 8,8 em $\mathrm{N}_{2}, 24,2$ em 20/80 $\mathrm{CO}_{2} / \mathrm{O}_{2}$ e 31,7 em 40/60 $\mathrm{CO}_{2} /$ $\mathrm{O}_{2}$.

Esta microbiota não foi afetada de uma forma significativa pelas atmosferas modificadas aqui estudadas, ou seja, as bactérias lácticas foram mais resistentes ao $\mathrm{CO}_{2}$, como já se constatou repetidamente [6, 14, 40, 46]. Ao comparar-se os tempos de duplicação destas bactérias que cresceram nas amostras armazenadas a $1^{\circ} \mathrm{C}$ (Tabela 1) (1,6 dia em ar, 1,7 em $\mathrm{N}_{2}$ e 2,5 em 20/80 e 40/60 $\mathrm{CO}_{2} / \mathrm{O}_{2}$ ), suspeita-se de seu crescimento por igual em todas as atmosferas.

Também se tem que ressaltar as diferenças apreciadas no desenvolvimento desta microbiota em carne suína [29]. As comparações dos tempos de duplicação e das taxas na fase estacionária de crescimento permitem deduzir, de uma maneira geral, que a carne suina fornece um melhor substrato para o desenvolvimento das bactérias lácticas. O motivo que explica esta situação, provavelmente, é a diferença de $\mathrm{pH}$ destas carnes. Os 5 ou 6 décimos de diferença facilitam o crescimento de muitos microrganismos na carne de peru $(\mathrm{pH} \sim 6,0)$, uma vez que nestas condições, as bactérias lácticas terão demasiado competidores para prevalecer. Em contrapartida, o $\mathrm{pH}$ normal da carne de porco (em torno de 5,6) inibe o crescimento de microrganismos importantes da deterioração da carne embalada em atmosfera modificada e, inclusive, detém o de outros, como o da Shewanella putrefaciens [20]. A idéia aqui esboçada de que o $\mathrm{pH}$ é o fator crítico e não a composição da carne se apóia em trabalhos que asseguraram que o tipo de carne não teve influência no desenvolvimento de um microrganismo determinado, a não ser o $\mathrm{pH}$, que foi o fator decisivo [11].

Já se comprovou também [24] que as bactérias lácticas junto com o Brochothrix thermosphacta, eram os microrganismos majoritários nos músculos de aves embalados a vácuo, $100 \%$ de $\mathrm{N}_{2}, 20 / 80 \mathrm{CO}_{2} /$ $\mathrm{O}_{2}$ e $100 \%$ de $\mathrm{CO}_{2}$ armazenadas a $3 \mathrm{e} 10^{\circ} \mathrm{C}$.

Como já mencionado, as atmosferas aqui estudadas não influenciaram na taxa da fase estacionária das bactérias lácticas. Como o restante dos grupos microbianos (exceto o $B$. thermosphacta) são inibidos pelo $\mathrm{CO}_{2}$, foi relativamente freqüente que as bactérias lácticas predominassem nas atmosferas mais seletivas ao final das experiências, chegando 
a ultrapassar os niveis de vida útil, como pode ser visto nas amostras embaladas em 40/60 $\mathrm{CO}_{2} / \mathrm{O}_{2}$ mantidas a $7^{\circ} \mathrm{C}$ (Figura 2 - MRS e Tabela 2). Estes resultados estão de acordo com os dados recopilados [16, 35]. Na literatura, são muitos os trabalhos que indicam que as bactérias lácticas podem predominar na carne embalada em atmosfera modificada [1, 4, 23, 37, 39].

Finalmente, pode-se afirmar que as bactérias lácticas podem crescer em todas as atmosferas aqui estudadas, com velocidades similares. Ademais, pode-se dizer que crescem relativamente bem em atmosfera modificada, e quando prevalecem na carne, podem cooperar no pro- longamento da vida-de-prateleira a mercê de diversos mecanismos.

\section{6 - Microrganismos crescidos em ágar VRBG}

Este meio é utilizado para a contagem presuntiva de Enterobacteriaceae em alimentos [38], sendo que, os dados obtidos das contagens efetuadas, considerar-seão enterobactérias, uma vez que não se pode garantir que todos os microrganismos que se desenvolveram neste meio sejam enterobactérias. Não obstante, a grande maioria dos microbiologistas o utiliza para este fim.
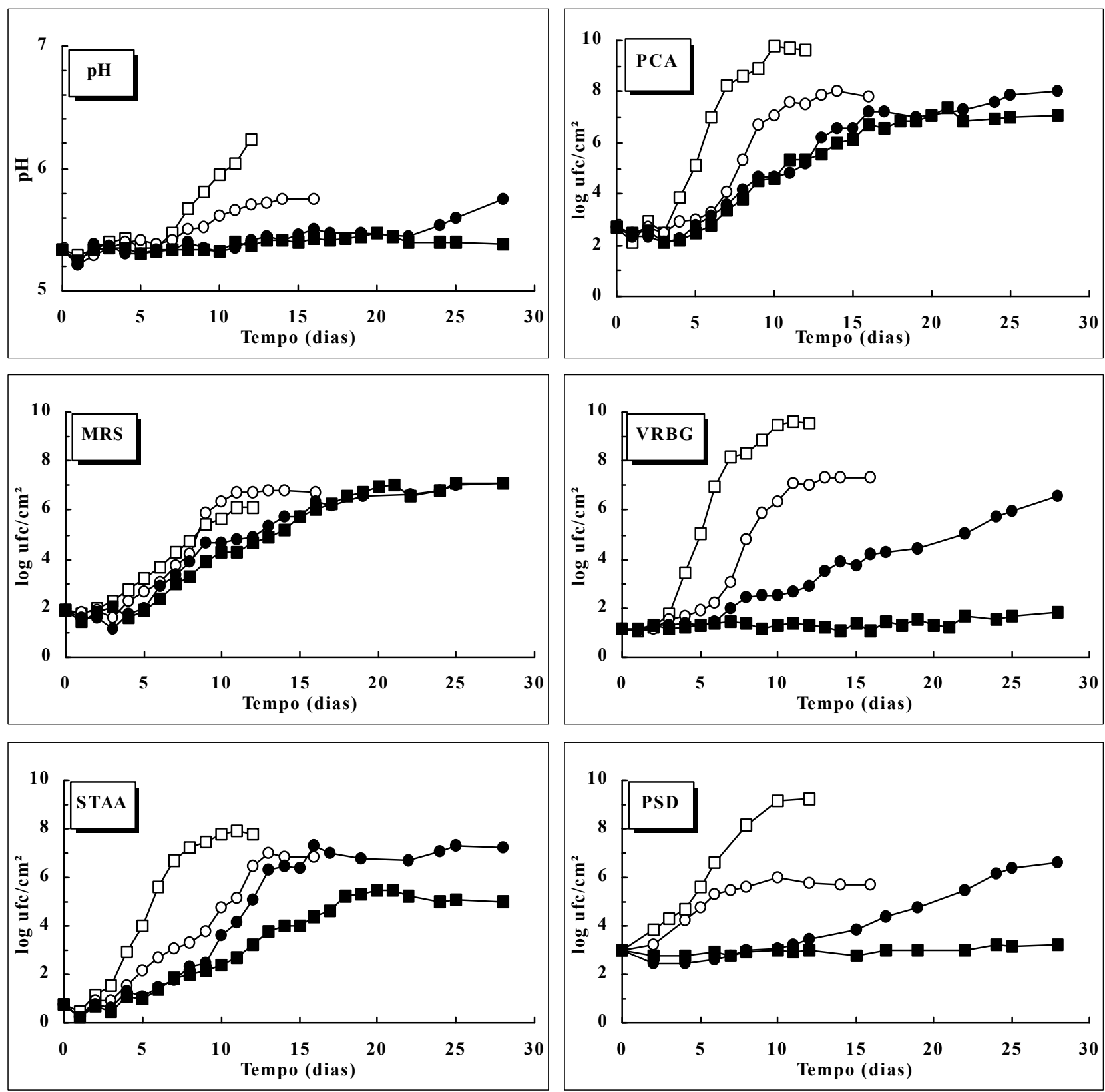

FIGURA 2. Evolução do $\mathrm{pH}$, microbiota total (PCA), bactérias lácticas (MRS), enterobactérias (VRBG), Brochothrix thermosphacta (STAA) e Pseudomonas spp. (PSD) em carne suina armazenada em $100 \%$ ar (口), $100 \% \mathrm{~N}_{2}(\mathrm{O}), 20 / 80 \mathrm{CO}_{2} / \mathrm{O}_{2}(\bullet)$ e $40 / 60 \mathrm{CO}_{2} / \mathrm{O}_{2}$ (匹) a $7^{\circ} \mathrm{C}$. 
As contagens no dia 0 foram de aproximadamente $16 \mathrm{UFC} / \mathrm{cm}^{2}$ (Tabelas 1 e 2). Em nenhum caso as enterobactérias predominaram ao principio das experiências.

A atmosfera foi decisiva para o crescimento desta microbiota. Como era de se esperar, as enterobactérias cresceram melhor em aerobiose, tanto a 1 como a $7^{\circ} \mathrm{C}$ (Figuras 1 e 2 - VRBG), alcançando taxas elevadas na fase estacionária $\mathrm{e}$, inclusive, chegaram a ser a microbiota dominante ao final nas amostras embaladas em $\mathrm{N}_{2}$ armazenadas a $7^{\circ} \mathrm{C}$ (Tabela 2). As atmosferas enriquecidas com $\mathrm{CO}_{2}$ inibiram claramente o seu desenvolvimento, somente detectando-se o crescimento deste grupo microbiano a $7^{\circ} \mathrm{C}$ (Tabela 2).

Dos resultados deste trabalho relativo às enterobactérias, caberia deduzir que estes microrganismos podem desenvolver-se com certa facilidade em ambientes com baixas pressões de $\mathrm{O}_{2}$ (vácuo e $100 \%$ de $\mathrm{N}_{2}$ ) e que são muito sensíveis ao $\mathrm{CO}_{2}$, sempre e quando o armazenamento se faça a uma temperatura de refrigeração baixa.

\section{7 - Brochothrix thermosphacta}

Devido à composição do meio de cultura STAA e às condições de incubação, pode-se dizer que praticamente todas as unidades formadoras de colônias desenvolvidas corresponderam à espécie $B$. thermosphacta. Este meio é totalmente seletivo para esta bactéria, podendose, inclusive, contar menos células do que realmente existe [25]. Isto devido ao caráter inibidor das substâncias (sulfato de estreptomicina, cicloheximida e acetato de tálio) adicionadas ao meio.

Esta bactéria se desenvolveu em aerobiose nas duas temperaturas estudadas (Figuras 1 e 2 - STAA), e como se esperava, multiplicou-se mais rápido à temperatura de $7^{\circ} \mathrm{C}$. Também cresceu a $100 \% \mathrm{~N}_{2}$ com um comportamento similar ao de aerobiose em relação à temperatura de armazenamento. A comparação dos parâmetros de crescimento nestas duas atmosferas permite dizer que esta bactéria se desenvolve melhor em condições aeróbias. Outros autores também observaram crescimento em carne de peru embalada em $100 \%$ de $\mathrm{N}_{2}$ [29], em carne de frango embalada em $100 \% \mathrm{~N}_{2}$ e a vácuo [24], em carne de porco a vácuo [10, 48] e em carne bovina em $100 \%$ de $\mathrm{N}_{2}$ [34] e a vácuo [42, 48].

É bem conhecida a relativa resistência do $B$. thermosphacta ao $\mathrm{CO}_{2}$ [44], entretanto, se comprovou, neste trabalho, que a inclusão deste gás na atmosfera, diminuiu o crescimento bacteriano, especialmente à temperatura de $1^{\circ} \mathrm{C}$. Quando a temperatura de armazenamento foi de $7^{\circ} \mathrm{C}$, este microrganismo multiplicou-se em todas as atmosferas, crescendo melhor em aerobiose, depois em $100 \%$ de $\mathrm{N}_{2}, 20 / 80 \mathrm{CO}_{2} / \mathrm{O}_{2}$ e, finalmente, em 40/60 $\mathrm{CO}_{2} / \mathrm{O}_{2}$, como se deduz ao comparar os parâmetros de crescimento deste microrganismo recorridos na Tabela 2.

Resumidamente, pode-se dizer que o $B$. thermosphacta sempre forma parte da microbiota contaminante da carne, e parece que o $\mathrm{pH}$ deste alimento não influencia no seu desenvolvimento. Esta bactéria se multiplica em presença de $\mathrm{O}_{2}$, inclusive, em pequenas concentrações (inferiores a $5 \%$ ) e pode chegar a ser o agente causal da alteração da carne. De todas as formas, o desenvolvimento desta bactéria é inibido, ainda que não impedido, pela presença de elevadas porcentagens de $\mathrm{CO}_{2}$.

\section{8 - Microbiota crescida em ágar PSD}

Assim como nos demais meios, não se identificaram os microrganismos que se desenvolveram neste meio de cultura. Sendo assim, não se pode garantir que todos eles pertençam ao gênero Pseudomonas. As contagens neste meio devem ser interpretadas com muita cautela. Indicou-se no título do trabalho original, que se trata de um meio seletivo para o isolamento rápido de pseudomonadaceas em carne de ave alterada [33]. Por outro lado, concluíram em seu artigo que não é um meio totalmente seletivo para pseudomonas, particularmente, quando a quantidade destes microrganismos é escassa em comparação com a de outros gêneros. Não obstante, é o meio mais adequado para o isolamento de pseudomonas de alimentos em que o número de pseudomonas é presumivelmente elevado.

Diante destes comentários, os autores destes trabalhos sustentam que o ágar PSD não é um meio seletivo, mas sim favorável para o isolamento e para a contagem de pseudomonas, sempre que se trabalhe com amostras procedentes de habitat aonde tais microrganismos podem crescer ativamente, ou seja, em aerobiose.

Como era de se esperar, as pseudomonas multiplicaram-se ativamente nas amostras embaladas aerobicamente e formaram parte da microbiota dominante ao final do período de armazenamento nas duas temperaturas estudadas (Tabelas 1 e 2).

$\mathrm{Na}$ atmosfera de nitrogênio, observou-se crescimento nas duas temperaturas estudadas (Figuras 1 e 2 - PSD). Apesar do caráter de aeróbias estritas das pseudomonas, elas podem multiplicar-se em atmosferas com baixas concentrações de $\mathrm{O}_{2}$ (na ordem de até $1 \%$ na atmosfera) [22]. Desta maneira, as colônias encontradas podem pertencer ao gênero Pseudomonas ou a outros grupos microbianos citados anteriormente, já que a atmosfera com $100 \%$ de $\mathrm{N}_{2}$ pode conter uma quantidade de $\mathrm{O}_{2}$ residual suficiente para suportar seu desenvolvimento. Quantidade esta, não detectada pela metodologia empregada na medida dos gases. Desde 1986 sabe-se que as pseudomonas podem multiplicar-se em atmosferas modificadas supostamente anaeróbias devido à dificuldade de eliminar totalmente o $\mathrm{O}_{2}$ [18]. Outros autores também detectaram certo desenvolvimento de pseudomonas em carne de peru embalada em $100 \% \mathrm{~N}_{2}$ e armazenada a 1 e $7^{\circ} \mathrm{C}$ [29], em carne de pato a vácuo e armazenada a $2^{\circ} \mathrm{C}$ [3], em carne bovina a vácuo e em $100 \% \mathrm{~N}_{2}$ a $2^{\circ} \mathrm{C}$ [34] e em carne de frango nas mesmas atmosferas a $2^{\circ} \mathrm{C}$ [24]. Todos estes autores encontraram contagens muito baixas nestas atmosferas; isto é, as pseudomonas são inibidas pela reduzida pressão de $\mathrm{O}_{2}$, mas ainda assim podem multiplicar-se. 
Neste trabalho, observou-se o desenvolvimento de microrganismos que crescem em ágar PSD em algumas amostras embaladas em atmosfera enriquecida com $\mathrm{CO}_{2} / \mathrm{O}_{2}$, tanto que, nas amostras com $20 / 80 \mathrm{CO}_{2} / \mathrm{O}_{2}$ armazenadas a $7{ }^{\circ} \mathrm{C}$ tiveram um tempo de duplicação de 1 dia e chegaram a contagens na fase estacionária superiores a $10^{6} \mathrm{UFC} / \mathrm{cm}^{2}$ (Tabela 2).

Em resumo, as pseudomonas, como aeróbias estritas, desenvolveram-se extraordinariamente bem em ar, sendo as responsáveis pela alteração da carne embalada em aerobiose. Enquanto que em anaerobiose (atmosfera de nitrogênio) ou nas atmosferas enriquecidas com $\mathrm{CO}_{2}$ foram detectadas em pequenas quantidades.

\section{4 - CONCLUSÕES}

De acordo com os resultados, pode-se concluir que: ao se aumentar a porcentagem de $\mathrm{CO}_{2}$ na atmosfera, se prolonga a fase de latência e reduz-se a velocidade do crescimento microbiano; que as atmosferas enriquecidas com $\mathrm{CO}_{2}$ são mais eficazes que a de nitrogênio, e obviamente, as fases de latência são mais curtas e as velocidades de crescimento mais rápidas a 7 do que a $1^{\circ} \mathrm{C}$, e; finalmente, que tanto a 1 como a $7^{\circ} \mathrm{C}$, a utilização das atmosferas modificadas retarda o crescimento das bactérias alterantes da carne de suíno, favorecendo o aumento da vida útil de no mínimo 2 vezes, principalmente, em atmosferas enriquecidas com $\mathrm{CO}_{2}$.

\section{5 - REFERÊNCIAS BIBLIOGRÁFICAS}

[1] ASENSIO, M. A.; ORDÓÑEZ, J. A.; SANZ, B. Effect of carbon dioxide and oxygen enriched atmospheres on the shelf-life of refrigerated pork packed in plastic bags. Journal of Food Protection, v.51, p.356-360, 1988.

[2] AVERY, S.M.; ROGERS, A.R.; BELL, G. Continued inhibitory effect of carbon dioxide packaging on Listeria monocytogenes and other microorganisms on normal $\mathrm{pH}$ beef during abusive retail display. International Journal of Food Science Technology, v.30, p.725-735, 1995.

[3] BARNES, E.M.; IMPEY, C.S.; GRIFFITHS, N.M. The spoilage flora and shelf-life of duck carcasses stored at 2 or $-1{ }^{\circ} \mathrm{C}$, in oxygen permeable, or oxygen impermeable film. British Poultry Science, v.20, p.491-500, 1979.

[4] BEUMER, R.R.; GIFFEL, M.C.te; BOER, E.de; ROMBOUTS, F.M. Growth of Listeria monocytogenes on slices cooked meat products. Food Microbiology, v.13, p.333-340, 1996.

[5] BLICKSTAD, E.; MOLIN, G. Carbon dioxide as a controller of the spoilage of pork, with special reference to temperature and sodium chloride. Journal of Food Protection, v.46, p.756-763, 1983.

[6] BRODY, A.L. 1996. Envasado de Alimentos en Atmósferas Controladas, Modificadas y a Vacio (ed. Brody, A.L.). Acribia, Zaragoza/España.

[7] CLARK, D.S.; LENTZ, C.P. Use of mixtures of carbon dioxide and oxygen for extending shelf-life of pre-packaged fresh beef. Canadian Institute of Food Science Technology Journal, v.6, p.194-196, 1973.

[8] DANIELS, J.A.; KRISHNAMURTHI, R.; RIZVI, S.S.H. A review of effects of carbon dioxide on microbial growth and food quality. Journal of Food Protection, v.48, p.532-537, 1985.

[9] DOHERTY, A.; SHERIDAN, J.J.; ALLEN, P.; MCDOWELL, D.A.; BLAIR, Y.S.; HARRINGTON, D. Growth of Yersinia enterocolitica O:3 on modified atmosphere packaged lamb. Food Microbiology, v.12, p.251-157, 1995.

[10] DOHERTY, A.; SHERIDAN, J.J.; ALLEN, P.; MCDOWELL, D.A.; BLAIR, I.S.; HARRINGTON, D. Survival and growth of Aeromonas hydrophila on modified atmosphere packaged normal and high $\mathrm{pH}$ lamb. International Journal of Food Microbiology, v.28, p.379-392, 1996.

[11] DUFFY, L.L.; VANDERLINDE, P.B.; GRAU, F.H. Growth of Listeria monocytogenes on vacuum-packed cooked effects of $\mathrm{pH}, \mathrm{a}_{\mathrm{w}}$, nitrite and ascorbate. International Journal of Food Microbiology, v.23, p.377-390, 1994.

[12] ENFORS, S.O.; MOLIN, G.; TERNSTRÖM, A. Effect of packaging under carbon dioxide, nitrogen or air on the microbial flora of pork stored at $4^{\circ} \mathrm{C}$. Journal of Applied Bacteriology, v.47, p.197-208, 1979.

[13] FANG, T.J.; LIN, L.W. Growth of Listeria monocytogenes and Pseudomonas fragi on cooked pork in a modified atmosphere packaging/nisin combination system. Journal of Food Protection, v.57, p.479-485, 1994.

[14] FARBER, J.M. Microbiological aspects of modifiedatmosphere packaging technology - A review. Journal of Food Protection, v.54, 58-70, 1991.

[15] FEY, M.S.; REGENSTEIN, J.M. Extending shelf-life of fresh, wet, red hake and salmon using $\mathrm{CO}_{2}-\mathrm{O}_{2}$ modified atmosphere and potassium sorbate ice at $1^{\circ} \mathrm{C}$. Journal of Food Science, v.47, p.1048-1054, 1982.

[16] GARCÍA DE FERNANDO, G.D.; MANO, S.B.; LÓPEZ, D.; ORDÓÑEZ, J.A. Eficacia de las atmósferas modificadas frente a los microorganismos patógenos psicrotrofos en alimentos proteicos. Microbiología SEM v.11, p.7-22, 1995.

[17] GIBSON, A.M.; BRATCHELL, N.; ROBERTS, T.A. The effect of sodium chloride and temperature on the rate and extent of growth of Clostridium botulinum type A in pasteurised pork slurry, Journal of Applied Bacteriology, v.62, p.479-490, 1987.

[18] GILL, C.O. The control of microbial spoilage in fresh meats. In: PEARSON, A.M.; DUTSON, T.R. (Eds) Advances in Meat Research. Meat and poultry microbiology. AVI Publishing Co., Inc., Westport, CT. London, 1986. p.4988.

[19] GILL, C.O.; HARRISON, C.L. The storage life of chilled pork packaged under carbon dioxide. Meat Science, v.24, p.313-324, 1989.

[20] GILL, C.O.; NEWTON, K.G. Spoilage of vacuum-packaged dark, firm, dry meat at chill temperatures. Applied Environment Microbiology, v.37, p.362-364, 1979.

[21] HOLLAND, G.C. Proceedings Meat Industry Research Conference, Chicago, IL, USA, p.21, 1980.

[22] HOOD, D.E.; MEAD, G.C. Modified atmosphere storage of fresh meat and poultry. In: PARRY, R.T. (Ed.) Principles and Applications of Modified Atmosphere Packaging of Food. Blackie Academic \& Professional, London, 1993. p.269-298.

[23] HUSS, H.H. Predicting shelf life in fish and meat products. Flair Flow Europe Reports; F-FE 230/96. Report, 1p. 1996.

[24] KAKOURI, A.; NYCHAS, G.J.E. Storage of poultry meat under modified atmospheres or vacuum packs: possible role of microbial metabolites as indicator of spoilage. Journal of Applied Bacteriology, v.76, p.163-12. 1994.

[25] LÓPEZ-GÁLVEZ, D.; HOZ, L.de la; BLANCO, M.; ORDÓÑEZ, J.A. (em impressão). 1998.

[26] LÓPEZ-GÁLVEZ, D.; HOZ, L.de la; ORDÓÑEZ, J.A. Effect of carbon dioxide and oxygen enriched atmospheres on microbiological and chemical changes in refrigerated tuna 
(Thunnus alalunga) steaks. Journal of Agriculture of Food Chemistry, v.43, p.483-490, 1995.

[27] MAN, J.C. de; ROGOSA, M.; SHARPE, M.E. A medium for the cultivation of Lactobacilli. Journal of Applied Bacteriology, v.23, p.130-135, 1960.

[28] MANO, S.B. Comportamiento de la microbiota natural y Listeria monocytogenes, Aeromonas hydrophilay Yersinia enterocolitica en carne envasada en atmósferas modificadas. Madri - Espanha, 1997. 225p. Exame de qualificação (Doutor em Medicina Veterinária) - Faculdade de Veterinária, Universidade Complutense de Madri (UCM).

[29] MANO, S.B.; ORDÓÑEZ, J.A.; GARCÍA DE FERNANDO, G.D. Aumento de la vida útil y microbiologia de la carne de pavo envasada en atmósferas modificadas. Revista Brasileira de Ciência Veterinária, v.6, n.2, p.55-65, 1999.

[30] MANU-TAWIAH, W.; MYERS, D.J.; OLSON, D.G.; MOLINS, R.A. Survival and growth of Listeria monocytogenes and Yersinia enterocolitica in pork chops packaged under modified gas atmospheres. Journal of Food Science, v.58, p.475-479, 1993.

[31] MARSHALL, D.L.; WIESE-LEHIGH, P.L.; WELLS, J.H.; FARR, A.J. Comparative growth of Listeria monocytogenes and Pseudomonas fluorescens on precooked chicken nuggets stored under modified atmospheres. Journal of Food Protection, v.54, p.841-843,851, 1991.

[32] McMUllen, L.M.; STILES, M.E. Changes in microbial parameters and gas composition during modified atmosphere storage of fresh pork loin chops. Journal of Food Protection, v.54, p.778-783, 1991.

[33] MEAD, G.C.; ADAMS, B.W.A selective medium for the rapid isolation of pseudomonads associated with poultry meat spoilage. British Poultry Science, v.18, p.661-670, 1977.

[34] NISSEN, H.; SØRHEIM, O.; DAINTY, R. Effects of vacuum, modified atmospheres and storage temperature on the microbial flora of packaged beef. Food Microbiology, v.13, p.183-191, 1996.

[35] NYCHAS, G. Modified atmosphere packaging of meats. In: SINGH, R.P.; OLIVEIRA, F.A.R. (Eds.) Minimal Processing of Foods and Process Optimization: an Interface. CRC Press Inc., London, 1994. p.417-436.

[36] ORDÓÑEZ, J.A.; LEDWARD, D.A. Lipid and myoglobin oxidation in pork stored in oxygen- and carbon dioxideenriched atmospheres. Meat Science, v.1, p.41, 1977.

[37] ORDÓÑEZ, J.A.; PABLO, B.de; PÉREZ DE CASTRO, B.; ASENSIO, M.A.; SANZ, B. Selected chemical and microbiological changes in refrigerated pork stored in carbon dioxide and oxygen enriched atmospheres. Journal of Agriculture of Food Chemistry, v.39, p.668672, 1991.
[38] OXOID Catálogo de Microbiologia. Unipath, 1996.

[39] PABLO, B.de; ASENSIO, M.A.; SANZ, B.; ORDÓÑEZ, J.A. The $\mathrm{D}(-)$ lactic acid and acetoin/diacetyl as potential indicators of the microbial quality of vacuum-packed pork and meat products. Journal of Applied Bacteriology, v.66, p.185-190, 1989.

[40] PARRY, Introduction. In: PARRY, R.T. (ed) Principles and Applications of Modified Atmosphere Packaging of Food. Blackie Academic \& Professional, London, 1993. p. $1-18$.

[41] PARDI, M.C.; SANTOS, I.F.dos; SOUZA, E.R.de; PARDI, H.S. Ciência, Higiene e Tecnologia da Carne. Ed. EDUFF/ UFG, Goiânia,V.1, 1995.

[42] PENNEY, N.; HAGYARD, C.J; BELL, R.G. Extension of shelflife of chilled slice roast beef by carbon dioxide packaging. International Journal of Food Science Technology, v.28, p.181-191, 1993.

[43] RÖNNER, U. Modified atmosphere packaging of non-respiring products. In: LEISTNER, L.; GORRIS, L.G.M. (Eds.) Food Preservation by Combined Processes. Final Report. FLAIR (Food Linked Agro-Industrial Research) Concerted Action No. 7, Subgroup B, 1994. p.51-58.

[44] SEIDEMAN, S.C.; VANDERZANT, C.; SMITH, G.C.; DILL, C.W.; CARPENTER, Z.L. Appearance of beef, pork and lamb stored in vacuum or modified gas atmospheres. Journal of Food Protection, v.43, p.252-258, 1980.

[45] SHERIDAN, J.J.; DOHERTY, A.; ALLEN, P.; MCDOWELL, D.A.; BLAIR, Y.S.; HARRINGTON, D. Investigations on the growth of Listeria monocytogenes on lamb packaged under modified atmospheres. Food Microbiology, v.12, p.259-266, 1995.

[46] SØRHEIM, O.; GRINI, J.A.; NISSEN, H.; ANDERSEN, H.J.; LEA, P. Pork loins stored in carbon dioxide. Colour and microbiological shelf life. Fleischwirtsch (English part), v.75, p.679-681, 1995.

[47] SPAHL, A.; REINECCIUS, G.; TATINI, S. Storage life of pork chops in $\mathrm{CO}_{2}$-containing atmospheres. Journal of Food Protection, v.44, p.670-673, 1981.

[48] TAYLOR, A.A.; DOWN, N.F.; SHAW, B.G. A comparison of modified atmosphere and vacuum skin packing for the storage of red meats. International Journal of Food Science \& Technology, v.25, p.98-109, 1990.

\section{6 - AGRADECIMENTOS}

Os autores agradecem à "Comisión Interministerial de Ciencia y Tecnología (CICYT)", projeto ALI 94-0350; "AAIR Concerted Action PL-920630 Physiology Food Poisoning Microorganisms" e CAPES-DAFA do Governo Brasileiro. 